\title{
Respiratory Muscle Training
}

National Cancer Institute

\section{Source}

National Cancer Institute. Respiratory Muscle Training. NCI Thesaurus. Code C160870.

A series of breathing and other exercises that are performed to improve the function of the respiratory muscles through resistance and endurance training. 